\title{
A IMPORTÂNCIA DAS TICs NO PROCESSO DE DESENVOLVIMENTO DA EDUCAÇÃO A DISTÂNCIA
}

\author{
Francisco Fernandes da Silva da Cruz ${ }^{1}$ \\ Neiliane Oliveira Morais²
}

\section{RESUMO}

A Educação a Distância (EaD) é uma das principais modalidades de ensino no Brasil; atualmente, diversos cursos, nos mais diferentes níveis de educação, são ofertados nessa modalidade, favorecendo, sobretudo, as camadas populares e os trabalhadores que precisam de uma forma flexível de estudo para o aperfeiçoamento ou obtenção de uma desejada formação acadêmica. $O$ advento das Tecnologias da Informação e Comunicação (TICs) proporcionou um grande avanço na modalidade de ensino supracitada, na medida em que elas popularizaram a EaD e permitiram que ela se tornasse uma das mais importantes formas de formação e qualificação profissional hoje. Em vista disso, este trabalho teve como proposta o estudo sobre a evolução histórica da $\mathrm{EaD}$, a fim de compreender como ela se desenvolveu. Além disso, outro foco desta pesquisa foi identificar a importância das TICs no processo de desenvolvimento estudantil, bem como a consolidação da modalidade em questão, como uma importante alternativa de estudos para uma parcela significativa da sociedade. $O$ presente trabalho foi desenvolvido por meio de uma pesquisa exclusivamente bibliográfica, com consultas a sites, livros, revistas, dissertações e teses que abordam o assunto em discussão. Os resultados confirmaram que as TICs têm um papel de extrema relevância ao desenvolvimento da $\mathrm{EaD}$, sendo elas, o principal veículo de propagação da modalidade de educação aqui referida.

Palavras-chave: Educação a Distância. TICs. Popularização.

\section{THE IMPORTANCE OF ICTS IN THE DEVELOPMENT PROCESS OF DISTANCE LEARNING}

\begin{abstract}
Distance Learning $(\mathrm{DL})$ is currently one of the main teaching modalities in Brazil, currently several courses, at different levels of education, are offered in this modality, favoring mainly the popular classes and workers who need a flexible way of studying, to improve

\footnotetext{
${ }^{1}$ Mestre em Química pela Universidade Federal do Maranhão. E-mail: bacanaceab@gmail.com

${ }^{2}$ Graduada em Música Licenciatura pela - Universidade Estadual do Maranhão - Núcleo de Tecnologias para

Educação - UEMANET. E-mail: neilianeoliveiramorais@gmail.com
} 
themselves or to obtain the desired academic education. The advent of Information and Communication Technologies (ICTs) provided a great advance in this teaching modality, as ICTs have popularized DL allowing it to become one of the most important forms of professional training and qualification today. For this reason, the purpose of this work was to study of the historical evolution of $\mathrm{DL}$, in order to understand how this teaching modality developed. In addition, another focus of this research was to identify the importance of ICTs in the student development process, as well as the consolidation of the modality in question as an important alternative of education for a significant portion of society. The present work was developed through exclusively bibliographical research, through consultations to websites, books, magazines, dissertations and theses that deal with the subject under discussion. The results confirm that ICTs have an extremely important role in the development of DL, as they are the main vehicle for propagating the modality of education mentioned here.

Keywords: Distance Education, ICTs, Popularization.

\section{LA IMPORTANCIA DE LAS TIC EN EL PROCESO DE DESARROLLO DE LA EDUCACIÓN A DISTANCIA}

\section{RESUMEN}

La Educación a Distancia (EaD) es actualmente una de las principales modalidades de enseñanza en Brasil, actualmente varios cursos, en los más diferentes niveles de formación, son ofrecidos en la modalidad a distancia, favoreciendo principalmente a las clases populares, a los trabajadores y a quienes necesitan una forma flexible de estudiar, para superar u obtener una formación académica deseada. La llegada de las tecnologías de la información y la comunicación (TIC) ha supuesto un gran avance en la modalidad educativa que se trata en este trabajo. Las TIC han popularizado el aprendizaje a distancia, permitiendo que se convierta en una de las formas de formación y cualificación profesional más importantes en la actualidad. La propuesta de este trabajo fue estudiar la evolución histórica de la educación a distancia, para entender cómo se ha desarrollado esta modalidad educativa. Además, otro de los objetivos de este trabajo fue conocer la importancia de las tecnologías de la información y la comunicación en el proceso de desarrollo y consolidación de la educación a distancia, como una importante alternativa de estudio para una parte importante de la sociedad. El presente trabajo se ha elaborado mediante una investigación exclusivamente bibliográfica, consultando páginas web, libros, revistas, disertaciones y tesis que tratan el tema. Los resultados confirman que las tecnologías de la información y la comunicación han desempeñado un papel muy importante en el desarrollo de la enseñanza 
a distancia, ya que son el principal vector de propagación de la modalidad de enseñanza aquí mencionada.

Palabras clave: Educación a distancia, TIC, popularización.

\section{INTRODUÇÃO}

O presente trabalho versa sobre a importância das Tecnologias da Informação e Comunicação (TICs), as quais ampliam a abrangência da Educação a Distância (EaD), e objetiva compreender a importância das TICs para a melhoria e avanço dessa modalidade educacional, bem como refletir quanto ao papel das referidas tecnologias para a expansão da $\mathrm{EaD}$, tornando essa modalidade de ensino uma das mais importantes formas de ensino e aprendizagem da atualidade.

As informações levantadas para a construção do trabalho foram obtidas por meio de uma pesquisa bibliográfica, colhendo apenas dados teóricos sobre o assunto em discussão.

Os pontos destacados fazem uma breve abordagem sobre a evolução histórica da EaD, apresentando acontecimentos importantes ao desenvolvimento dessa modalidade no Brasil. Além do mais, esta pesquisa trata da importância do uso dessas ferramentas como potencializadores da EaD, tendo em vista que as referidas tecnologias têm a possibilidade de atingir um grande número de indivíduos e podem ser aplicadas à educação como instrumento para a melhoria do processo de ensino e aprendizagem dos sujeitos envolvidos.

Finalizando este trabalho, apresentam-se as principais conclusões obtidas na pesquisa, destacando que as TICs foram muito importantes para que a EAD se tornasse bastante popular na atualidade.

\section{DESENVOLVIMENTO}

Aeducação a distância, atualmente, é uma importante ferramenta de democratização do ensino, com capacidade de atingir uma grande quantidade de alunos, simultaneamente, de forma efetiva e sem perder a qualidade do serviço oferecido. (ALVES, 2011).

No período da pandemia causada pelo novo coronavírus, a EaD se tornou ainda mais popular enquanto ferramenta educacional. Essa modalidade de ensino garantiu a continuidade das atividades educacionais, favorecendo a progressão dos estudantes em seus aprendizados, tendo a possibilidade de não retardar a sua formação, em virtude da suspensão das aulas presenciais.

Para uma melhor compreensão a respeito da EaD, é necessário fazer uma breve abordagem sobre o seu conceito, considerando que ela pode ser definida, não com apenas um conceito, mas com um conjunto de informações que defina as suas características. 
Peters (1973 apud NUNES, 1993, p. 6) diz que:

Educação/Ensino a distância é um método racional de partilhar conhecimento, habilidades e atitudes, através da aplicação da divisão do trabalho e de princípios organizacionais, tanto quanto pelo uso extensivo de meios de comunicação, especialmente para o propósito de reproduzir materiais técnicos de alta qualidade, os quais tornam possível instruir um grande número de estudantes ao mesmo tempo enquanto esses materiais durarem. É uma forma industrializada de ensinar e aprender.

O conceito apresentado na citação acima pode ser complementado, levando em consideração o pensamento de Moore (1990 apud BELLONI, 2002, p.31):

Educação a distância é uma relação de diálogo, estrutura e autonomia que requer meios técnicos para mediatizar esta comunicação. Educação a distância é um subconjunto de todos os programas educacionais caracterizados por: grande estrutura, baixo diálogo e grande distância transacional. Ela inclui também a aprendizagem.

No escopo da política educacional brasileira, encabeçada pelo Ministério da Educação (MEC), o Decreto $n^{\circ} 5.622$, de dezembro de 2005, documento que regulamentou a EAD no Brasil, traz, em seu artigo 10, a afirmação de que essa modalidade educacional, na qual a mediação didático-pedagógica ocorre com a utilização de tecnologias, permite que estudantes e professores desenvolvam atividades educativas em lugares ou tempos diversos. (BRASIL, 2005).

A definição de EaD se constrói ao longo da sua trajetória, pois, a cada tecnologia que é incorporada, o processo de EaD confere um novo aspecto a essa modalidade de ensino. Diante disso, conceituá-la é encontrar uma maneira de expressar, por meio de palavras, e de forma resumida, as características e benefícios oferecidos a quem a ela recorre. (ALVES, 2011).

Entre essas características importantes da EaD, destaca-se a não obrigatoriedade da presença de professores e alunos no mesmo espaço físico, permitindo que o processo de ensino e aprendizagem seja síncrono ou assíncrono, em que professores e alunos possam ter flexibilidade na realização de suas atividades, sem perder a qualidade de um bom ensino. (RODRIGUES et al., 2021).

Moran (2009, apud SILVEIRA et al., 2010, p. 55) diz que:

No contexto da EaD, a partir da popularização da televisão e da teledramaturgia, a interação com o professor tradicionalmente se efetivou por meio de materiais impressos e videoaulas, recursos estes aos quais, mais recentemente, somaram-se as teleaulas. No que diz respeito à diferença entre teleaulas e videoaula, adotaremos neste artigo a conceituação estabelecida. $\mathrm{O}$ autor entende teleaulas como aquela aula realizada a distância na qual o professor é visto pelos alunos ao vivo, em tempo real, e videoaula como a aula gravada à qual posteriormente o aluno tem acesso. 
A modalidade de ensino em discussão não é um fenômeno novo, as primeiras experiências foram realizadas no século XV. Apesar de haver divergência a respeito do surgimento da educação a distância, um fato é verdadeiro: o surgimento da tecnologia foi muito importante para a sua consolidação. (HERMIDA; BONFIM 2006).

Os autores Cardoso, Sabbatini e Bastos (2000), consideram que a origem da EaD está relacionada com a criação dos cursos por correspondência, no final do século XVIII. De acordo com os mesmos, a invenção do sistema de correios possibilitou a realização de cursos à distância, pois permitia a troca de mensagens entre os envolvidos no processo de ensino.

Maia e Mattar (2007) ressaltam que a EaD tem a idade da escrita, ou seja, desde que essa representação gráfica foi inventada, a prática de educação a distância começou a existir. Hermida e Bonfim (2006), destacam que a invenção da imprensa, combinada com a invenção do sistema de correios, possibilitaram a ampliação da EaD.

Bittner e Mollory (1933 apud MOORE; KEARSLEY, 2008, p. 25-26) dizem que:

A correspondência pelo correio foi usada pela primeira vez para cursos de educação superior pelo Chautauqua Correspondence College. Fundado em 1881, foi rebatizado de Chautauqua College of Liberal Arts em 1883 e autorizado pelo Estado de Nova York a conhecer diplomas e graus de bacharel por correspondência. Aproximadamente na mesma época e não muito distante de Chautauqua, em Scranton, Pensilvânia, uma escola vocacional privada denominada Colliery Engineer School of Mines, começou a oferecer um curso por correspondência sobre segurança nas minas. $O$ sucesso desse curso foi tão grande que a escola logo começou a oferecer outros cursos e, em 1891, passou a se chamar International Correspondence Schools (ICS). Agora faz parte do conglomerado editorial Thomson, sendo conhecida como Education Direct.

AEaD, a partir de então, passou a ser amplamente utilizada por muitas instituições de ensino em diferentes países. Ela era utilizada em todas as etapas de educação e, também, em diversos ramos do ensino, como no ensino profissionalizante, científico e técnico. (MOORE; KEARSLEY, 2008).

Na trajetória histórica da evolução da EAD, percebe-se a sua grande versatilidade em se adaptar à realidade de desenvolvimento social para se tornar cada vez mais eficiente. Nesse contexto, Moore e Kearsley (2008) apresentam que a EAD evoluiu ao longo da história, por meio de gerações específicas, levando em consideração a tecnologia existente na sociedade.

Maia e Mattar (2007) especificam as três gerações históricas da evolução do ensino a distância, a saber: primeira, segunda e terceira geração. A primeira geração é caracterizada pelo ensino por correspondência, no qual são utilizados materiais impressos; a segunda é representada pelas novas mídias e pela universidade, fazendo uso de rádio, $\mathrm{TV}$, vídeos e fitas cassetes; e a terceira geração, também conhecida como EaD on-line, na qual há a presença da internet, do MP3, do Ambiente Virtual de Aprendizagem (AVA), de vídeos, de animações, de ambientes 3D, de redes sociais e de fóruns. 
A primeira geração, segundo Moore e Kearsley (2008), ocorreu por meio dos cursos por correspondências, aproveitando o surgimento do sistema de correios, conforme abordado anteriormente.

A segunda geração se deu pelo sistema de rádio e televisão, o qual deu um significativo avanço na modalidade de ensino em discussão. Moore e Kearsley (2008, p. 25) dizem que:

\begin{abstract}
Quando o rádio surgiu como uma nova tecnologia no início do século $X X$, muitos educadores nos departamentos de extensão das universidades reagiram com otimismo e entusiasmo. A primeira autorização para uma emissora educacional foi concedida pelo governo federal à Latter Day Saint' da University of Salt Lake City em 1921. Em fevereiro de 1925, a State University of lowa oferecia seus primeiros cursos de cinco créditos por rádio. Dos 80 alunos que se matricularam naquele primeiro semestre, 64 acabaram completando o programa do curso na universidade. No entanto, o rádio como tecnologia de divulgação da educação não fez jus às expectativas. $O$ interesse restrito demonstrado pelo corpo docente e pela direção da universidade, assim como o amadorismo daqueles poucos professores que mostraram interesse provaram ser um recurso medíocre para o compromisso firme da mídia de radiotransmissão, exibido pelas emissoras comerciais que desejavam os cursos como meio para conseguir anúncios.
\end{abstract}

Embora o rádio tenha representado um grande avanço, conforme a citação acima, ele não atendeu às expectativas. A televisão, porém, possibilitando a transmissão de imagem e som simultaneamente, se mostrou mais eficiente e agradou mais que a difusão radiofônica.

Moore e Kearsley (2008, p. 32) dizem que:

A televisão educativa estava em desenvolvimento já em 1934. Naquele ano, a State University of lowa realizou transmissões pela televisão sobre temas do tipo higiene oral e astronomia; em 1939, a estação da universidade havia transmitido quase 400 programas educacionais. Naquele mesmo ano, uma escola de nível médio em Los Angeles fez experiências com a televisão na sala de aula. Após a Segunda Guerra Mundial, quando foram distribuídas as frequências de televisão, 242 dos 2.053 canais foram concedidos para uso não comercial. Além da transmissão de programas nesses canais, alguns dos melhores programas educativos foram introduzidos por emissoras comerciais. A NBC levou ao ar o Continental Classroom, da Johns Hopkins University, que algumas instituições de educação superior usaram para instrução valendo créditos, e a CBS transmitiu seu Sunrise Semester. Embora as estações comerciais tenham desistido dessa oferta de serviços públicos, a televisão educativa teve mais sucesso que a rádio educativa por causa das contribuições da Fundação Ford.

Nessa geração, marcada pelo uso do sistema de televisão, houve a implantação de alguns programas destinados à colaboração com o desenvolvimento dos cursos a distância, como os serviços fixos de televisão educativa e os telecursos, por meio de televisão a cabo. Dessa forma, a EaD se popularizou cada vez mais na sociedade, contribuindo de modo significativo para o processo de aproximação entre a educação formal e os indivíduos da sociedade. 
De acordo com Alves (2011), no ano de 1904, iniciaram-se os primeiros cursos por correspondência aqui no Brasil. No entanto, esses cursos se tornaram mais recorrentes somente em 1930, pois o ensino profissionalizante, por meio dos correios, se tornou uma grande oportunidade de acesso ao conhecimento às pessoas que residiam nos mais diferentes pontos do país.

Hermida e Bonfin (2006, p. 7) dizem que:

A EaD passou a ser conhecida no Brasil a partir de projetos de ensino supletivo via televisão e fascículos. Porém, adquiriu popularmente o significado de "educação pela televisão", tal como, para a maioria das pessoas, os telecursos eram (e são ainda) "cursos pela televisão".

Nessa abordagem sobre a implantação da Educação a Distância no Brasil, cabe destacar o trabalho de Nunes (1993), afirmando que essa modalidade de educação, no Brasil, teve início com o Instituto Monitor, no ano de 1929, e com o Instituto Universal Brasileiro, no ano de 1941. A partir de então, ela ganhou espaço como alternativa para capacitar e preparar profissionais para o mercado e para a atuação na sociedade.

Na década de 1950, a EaD foi marcada pela criação de universidades e cursos que utilizavam essa modalidade para o treinamento e capacitação de profissionais em diversas áreas de atuação. As orientações eram transmitidas pelo rádio e contribuíram de forma significativa para o aperfeiçoamento profissional de muitos cidadãos que não tinham condições de estar presencialmente em uma sala de aula.

Hermida e Bonfim (2006) enfatizam que, na década de 1950, houve iniciativas dos setores público e privado no que tange à implantação da EaD. Destaca-se aqui o sistema de radiodifusão lançado pela Arquidiocese de Natal, no Rio Grande do Norte, projeto que serviu de inspiração para a criação do Movimento de Educação de Base (MEB), no ano de 1958, cujo objetivo era proporcionar oportunidade de estudo a muitas pessoas por meio dessa modalidade de ensino.

Na década de 1960, houve a criação do Projeto Minerva, com a finalidade de atingir um grande número de pessoas e desenvolver as suas potencialidades. (CARVALHO, 2013).

Monteiro (2001) aponta que o Projeto Minerva orientava pedagógica e profissionalmente e contava, também, com uma programação cultural, concentrando-se no ensino supletivo e na educação de base. Desse modo, as principais características eram:

Contribuição para renovação e o desenvolvimento do sistema educacional e para a difusão cultural, conjugando o rádio e outros meios; Complementação ao trabalho desenvolvido pelo sistema regular de ensino; Possibilidade de promoção da educação continuada; Divulgação de programação cultural de acordo com o interesse da audiência; Elaboração de textos didáticos de apoio aos programas instrutivos; Avaliação dos resultados da utilização dos horários da Portaria número 408/70 pela emissora de rádio; O rádio foi escolhido quanto à idealização do projeto em função dos seguintes aspectos: Custo mais baixo no que se referia à aquisição 
e manutenção de aparelhos receptores; A familiaridade da clientela com o referido meio de comunicação. (CASTRO, 2007 apud CARVALHO, 2013, p. 21).

Esse projeto durou até a década de 1980, sob diversos questionamentos sobre a sua eficácia; além do que, havia a suspeita de que se fazia o uso político dos meios de comunicação para fortalecer o regime dominante: a Ditadura Militar.

Nessa discussão, é importante mencionar que, na década de 1970, a Fundação Roberto Marinho (FRM) iniciou os Telecursos, destinados ao ensino fundamental e ensino médio ( $1^{\circ}$ e $2^{\circ}$ grau). A FRM, com base em toda a sua experiência em Educação a Distância, criou o projeto "Telecurso 2000", que, pela primeira vez, foi ao ar em 1995. (SILVA, 2013).

O Telecurso 2000 ainda está em funcionamento, proporcionando oportunidade de estudo para jovens de diferentes regiões do Brasil; algumas emissoras exibem as aulas em canal aberto, o qual proporciona aprendizagem em todo o território nacional.

Silveira et al. (2010, p. 25) dizem que:

Ainda, apesar de as videoaulas produzidas para o Telecurso $2^{\circ}$ Grau e posteriormente para o Telecurso $1^{\circ}$. Grau oscilarem entre o modelo de aula tradicional, e um modelo de aula que se aproximava do documentário, elas eram produzidas por uma equipe técnica de elevada qualidade, vinculada à produção televisiva, com profissionais contratados junto ao mercado com recursos das Organizações Globo, ou cedidos do próprio quadro da empresa

De acordo com dados da literatura, o Telecurso 2000 foi desenvolvido por meio da parceria entre as Organizações Globo e a Fundação Padre Anchieta, sendo está a responsável pelo material didático e pelas pesquisas para a produção do conteúdo. A equipe de produção e gravação das aulas ficava a cargo das Organizações Globo, e isso ocorria sem as devidas interações entre as duas organizações, havendo, desse modo, grande possibilidade de existirem divergências entre o objetivo do material didático e o material audiovisual produzido. (SILVEIRA et al., 2010).

O caminho do estabelecimento definitivo da EaD no Brasil foi permeado por problemas em diversos setores da sociedade. Destacam-se aqui as mudanças no cenário político do país, as quais provocaram diversas modificações no sistema educacional. A década de 1980 foi marcada por profundas alterações em todos os campos da sociedade brasileira, em decorrência da luta da sociedade pela democracia e, ainda, pelo fim da Ditadura Militar.

Carvalho (2013, p. 21) diz que:

No final da década de 80 e com o fim do período da ditadura militar, o Ministério da Educação começou a desenvolver novas iniciativas. A partir de então foram criadas várias portarias que incentivaram o crescimento da educação à distância no Brasil, como a portaria $\mathrm{n}^{\circ} 511$ de 27 de setembro de 1988 que constitui um grupo 
de trabalho para elaborar políticas relacionadas à educação à distância e formular novas propostas de cursos para serem ofertados nessa metodologia, utilizando para esses fins as correspondências e as técnicas correlatas. O MEC criou também, nessa mesma época, o Instituto Nacional de Pesquisas Educacionais (INEP) e a Coordenadoria de Educação a Distância, sendo que esta última tinha como principal objetivo fomentar estudos, pesquisas e programas na área de EAD.

No ano de 1989, o MEC lançou projetos para encaminhar e viabilizar a implantação da EaD no Brasil, que fossem capazes de atender aos três graus de ensino no território nacional. A modalidade, até então, tinha um caráter emergencial de suprir a defasagem escolar da sociedade; na década de 1990, porém, a Lei no 9.394, de 20 de dezembro de 1996 que estabelece as diretrizes e bases da educação nacional, a formalizou, conferindoIhe características próprias. (BRASIL, 1996).

Carvalho (2013, p. 23) afirmou que:

A partir da aprovação desta lei, datada de 20 de dezembro de 1996, a EAD, passa a ser uma modalidade de ensino, que goza de características próprias e diferenciadas, e que possui como principal foco, a mediação didático pedagógica nos processos de ensino aprendizagem, se utilizando para tanto de novos meios e tecnologias de informação e comunicação, onde estudantes e professores, poderão desenvolver suas atividades educacionais em lugares ou campos diferentes.

O artigo 80 da referida Lei trata, especificamente, da Educação a Distância, definindo normas, direitos e deveres referentes a essa modalidade de ensino. Entre as vantagens que ela confere à $\mathrm{EaD}$, destacam-se: custo de transmissão reduzido e concessões de canais com finalidades exclusivamente educativas. (BRASIL, 1996).

Desde então, no Brasil, a EaD vem sendo cada vez mais difundida e requisitada por estudantes de diferentes áreas e campos de atuação profissional e, portanto, exerce um papel de grande relevância para o desenvolvimento educacional do país.

Após essa explanação sobre o histórico da $\mathrm{EaD}$, percebe-se que ela utilizou a tecnologia disponível para alcançar o seu público, e o surgimento de meios de comunicação cada vez mais massivos proporcionou uma grande popularização da modalidade em discussão neste trabalho. (VILAÇA, 2010).

O fenômeno EaD vive um grande momento de expansão no Brasil e no mundo. A modalidade tem um crescimento exponencial, o que é perceptível pelo grande número de instituições públicas e privadas que oferecem algum curso a distância. $\mathrm{O}$ crescimento da oferta de cursos EaD mobiliza diversos profissionais que dão suporte para o sucesso desse tipo de ensino, entre os quais, professores e outros profissionais da educação; técnicos de som e imagem; publicitários; empresários e outros. (MAIA; MATTAR, 2007).

Dando continuidade às discussões deste trabalho, inicia-se aqui uma abordagem sobre a importância das TICs para a evolução da Educação a Distância, considerando os 
conceitos e os principais acontecimentos referentes à tecnologia, os quais possibilitaram à EaD tamanha expressividade.

Miranda (2007, p. 43) diz que:

O termo Tecnologias da Informação e Comunicação (TIC) refere-se à conjugação da tecnologia computacional ou informática com a tecnologia das telecomunicações e tem na Internet e mais particularmente na World Wide Web (WWW) a sua mais forte expressão. Quando estas tecnologias são usadas para fins educativos, nomeadamente para apoiar e melhorar a aprendizagem dos alunos e desenvolver ambientes de aprendizagem podemos considerar as TIC como subdomínio da Tecnologia Educativa.

As TICs surgiram no contexto da Terceira Revolução Industrial, e, após muito tempo de aprimoramento e desenvolvimento de novas ferramentas para essa área, no ano de 1990, essas tecnologias começaram a ser popularizadas na sociedade. (PAESE, 2012).

As TICs têm sido muito utilizadas no processo de ensino e aprendizagem, proporcionando inúmeras vantagens e mudanças na forma de educar, e o seu advento, indiscutivelmente, gerou novos desafios e oportunidades à escola, sobretudo, no que tange à representação e à comunicação de ideias, principais fatores considerados na atividade educativa.

Para Brandão (2010), as TICs devem ser um dos instrumentos para a construção do conhecimento. Dessarte, atualmente, são importantes ferramentas para a educação das crianças e dos adolescentes, uma vez que eles "vivem" tecnologias, e quem não vive, sonha em viver. Em outras palavras, a tecnologia é o mundo deles, e isso é fato; portanto, não se pode ignorar esses potenciais.

Dourado et al. (2014, p. 357) dizem que:

No presente século, é impossível viver neste mundo globalizado sem utilização das TIC, definidas como tecnologias e ferramentas que servem para compartilhar, distribuir e reunir informação. Elas constituem um conjunto de recursos tecnológicos que as pessoas utilizam para se comunicarem entre si. Essas formas de difundir informações, tais como a televisão, jornal, web sites, internet, rádio, revistas, livros constituem-se em canais de acesso à comunicação e informação. Embora as TIC estejam constituídas de uma vasta variedade de possibilidades disponíveis às pessoas, este caminho ainda não está ao alcance de todos.

No campo educacional, as tecnologias na área das comunicações possibilitaram uma democratização do ensino, utilizando-se do virtual para garantir aprendizado aos indivíduos que optarem pela modalidade de ensino a distância (PAESE, 2012). A utilização de Ambientes Virtuais de Aprendizagem (AVAs) tem ganhado um significativo espaço, numa perspectiva de interação e construção colaborativa de conhecimento.

$\mathrm{Na}$ conjuntura atual, os recursos tecnológicos permitem feedback em um curto espaço de tempo; é como se o estudante da modalidade a distância estivesse presente 
em um ambiente físico de interação com o professor e com os demais colegas. Ademais, a troca de informações entre diversos indivíduos de diferentes regiões do país e do mundo faz da EaD uma importante ferramenta de formação profissional.

O apoio das TICs para o crescimento da EaD proporcionou, e continua proporcionando, que essa modalidade de educação se torne uma alternativa viável, para que jovens e adultos tenham a oportunidade de estudar dentro de suas condições e disponibilidade. Quanto à importância das tecnologias como recurso de mediação do processo de ensino e aprendizagem, sendo estas o principal suporte para a educação a distância na era atual.

Almeida (2003, p. 330) destaca que:

[...] reavivou as práticas de EAD devido à flexibilidade do tempo, quebra de barreiras espaciais, emissão e recebimento instantâneo de materiais, o que permite realizar tanto as tradicionais formas mecanicistas de transmitir conteúdos, agora digitalizados e hipermidiáticos, como explorar o potencial de interatividade das TIC e desenvolver atividades à distância com base na interação e na produção de conhecimento.

Atecnologia da informação contribuiu de forma significativa para o desenvolvimento da EaD, e, certamente, a presença das TICs no contexto da Educação a Distância tem sido algo crucial para o desenvolvimento desse tipo de ensino, na medida em que proporciona uma mediação rápida e precisa entre os sujeitos envolvidos no processo educacional.

A mediação da tecnologia é um fator de muita importância para o fortalecimento dessa modalidade, sendo que a utilização das TICs aproxima os sujeitos da aprendizagem, de modo que estabelece o desenvolvimento de uma comunicação que permite a rápida troca de informação e conhecimento entre professor, aluno e instituição.

As TICs permitem que a Educação a Distância atinja uma grande diversidade de pessoas, fazendo dela uma importante alternativa para quem deseja estudar de acordo com a sua disponibilidade de tempo.

É importante destacar, nessa abordagem, algumas das principais tecnologias aplicadas à modalidade em questão, conforme cita Almeida Júnior (2013 apud FERREIRA et al., 2017, p. 347):

O AVA (ambiente virtual de aprendizagem) - o aluno acessa, pelo computador, para comparecer às aulas e cumprir as atividades. O estudante recebe uma senha, entra na "sala de aula virtual" de qualquer lugar e em qualquer horário, basta estar conectado à Internet. No ambiente, ficam disponíveis os teores do curso e ferramentas de interação, como videoaula, áudio e videoconferências, chats, fóruns e bibliotecas virtuais.

Os Ambientes Virtuais de Aprendizagem (AVAs) são na verdade uma forma de promover a interação entre professor, aluno e outro tipo de apoio para os estudantes, em um curto período de tempo, propiciando uma aprendizagem de qualidade. 
Segundo Almeida Junior (2013 apud FERREIRA et al., 2017, p. 347):

Videoaula - são aulas gravadas que o aluno pode acessar quando quiser. Elas podem combinar a fala do professor com apresentações, imagens, sons e interatividade. São desenhadas de forma a tornar o conteúdo do curso atrativo, prendendo a atenção do aluno pelo tempo necessário para que ele compreenda a matéria.

Além dessas tecnologias já citadas, os autores destacam que as bibliotecas virtuais permitem aos estudantes acesso a materiais didáticos rápida e precisamente, e, para atender às necessidades dos alunos 24 horas por dia, 7 dias por semana, elas contam com acervos virtuais, onde é possível baixar materiais de estudo em formato digital. (ALMEIDA JUNIOR, 2013 apud FERREIRA et al., 2017, p. 347).

Essas ferramentas contribuíram e continuam sendo de grandiosa importância para o sucesso da EaD, o qual se torna possível devido à evolução das TICs. (FERREIRA et al., 2017, p. 347).

Ressalta-se, no entanto, que tais recursos exigem profissionais capacitados para colocá-los em funcionamento; além disso, a figura do professor continua sendo essencial, mesmo quando se utilizam as ferramentas tecnológicas apenas como um suporte para o processo de ensino e aprendizagem.

Moran (1997, p. 145) diz que:

As tecnologias de comunicação não substituem o professor, mas modificam algumas das suas funções. A tarefa de passar informações pode ser deixada aos bancos de dados, livros, vídeos, programas em CD. O professor se transforma agora no estimulador da curiosidade do aluno por querer conhecer, por pesquisar, por buscar a informação mais relevante. Num segundo momento, coordena o processo de apresentação dos resultados pelos alunos. Depois, questiona alguns dos dados apresentados, contextualiza os resultados, os adapta à realidade dos alunos, questiona os dados apresentados. Transforma informação em conhecimento e conhecimento em saber, em vida, em sabedoria- o conhecimento com ética.

Eles permitiram longo alcance e rapidez na troca de informações, no processo pedagógico dessa modalidade de ensino, tornando-a cada vez mais popular e requisitada na sociedade.

Perante o grande impacto positivo que as TICs têm proporcionado na Educação a Distância, é possível dividir a sua história em dois grandes períodos: um anterior e um posterior à implantação das referidas tecnologias.

Moran (2004, p. 3 apud PAESE, 2012, p. 4) diz que:

[...] antes o professor só se preocupava com o aluno em sala de aula. Agora, continua com o aluno no laboratório (organizando a pesquisa), na Internet (atividades a distância) e no acompanhamento das práticas, dos projetos, das experiências que ligam o aluno à realidade, à sua profissão (ponto entre a teoria e a prática). Antes o professor se restringia ao espaço da sala de aula. Agora precisa aprender 
a gerenciar também atividades à distância, visitas técnicas, orientação de projetos e tudo isso fazendo parte da carga horária da sua disciplina, estando visível na grade curricular, flexibilizando o tempo de estada em aula e incrementando outros espaços e tempos de aprendizagem.

Diante dessa realidade, é necessário compreender que existem normas que regulamentam o funcionamento da EaD e que devem ser seguidas pelas instituições que oferecem ao público essa modalidade de ensino, a fim de que ela não se torne apenas um meio de obtenção de diploma ou certificados, sem o conhecimento devido para o exercício de determinada profissão ou cargo.

Atualmente, com a grande popularização dos meios de comunicação, proporcionada pelo avanço tecnológico, a Educação a Distância se tornou muito acessível à sociedade, exigindo mais atenção do poder público no que se refere às políticas voltadas para essa área.

Kenski (2003, p. 95) diz que:

A relação entre educação e novas tecnologias requer novos posicionamentos ligados à política e à gestão da educação. Esses novos posicionamentos dizem respeito à delimitação clara do papel do Estado na educação; aos objetivos e finalidades da educação em face das novas demandas sociais; à estrutura organizacional das instituições de ensino de todos os níveis; ao financiamento da educação; à universalização e à democratização do acesso a esses novos ambientes tecnológicos, por onde também se dá e se faz educação; às formas de valorização do magistério e às articulações com outras esferas sociais.

A cada dia, a EaD ganha mais espaço no meio educacional; a sua flexibilidade e o atual cenário tecnológico, favorável à troca rápida de informações, permitem que o estude a distância seja uma importante alternativa para quem quer estudar, e não tem tempo disponível para frequentar aulas presenciais.

\section{CONSIDERAÇÕES FINAIS}

A história da Educação a Distância está intimamente ligada à evolução tecnológica. A invenção da escrita, da imprensa e, notadamente, o advento dos recursos tecnológicos na área da comunicação favoreceram e proporcionaram o grande sucesso da EaD.

Diversos projetos educacionais, desenvolvidos no Brasil e no mundo, utilizaram a EaD para resolver problemas emergenciais referentes à educação e à escolarização da sociedade.

Regulamentada por lei, no Brasil, a Educação a Distância cumpre um importante papel no que concerne à formação e à capacitação profissional. Várias instituições brasileiras oferecem cursos de graduação, pós-graduação e aperfeiçoamento profissional por meio 
dessa modalidade de ensino que, dessa forma, eleva a qualidade dos serviços prestados, bem como o nível de escolaridade da sociedade brasileira.

Os AVAs, as videoaulas, as videoconferências, os chats e os "bate-papos" são algumas das ferramentas relacionadas às Tecnologias da Informação e Comunicação que estão à disposição da EaD, possibilitando-Ihe mais abrangência.

Diante disso, considera-se que as TICs são as principais responsáveis pela popularização da EaD, sendo consideradas ferramentas alternativas para a formação e capacitação de profissionais que atuam em diversas áreas.

\section{REFERÊNCIAS}

ALMEIDA, Maria Elizabeth Bianconcini de. Educação à distância na internet: abordagens e contribuições dos ambientes digitais de aprendizagem. Revista Educação e Pesquisa. São Paulo, v. 29, n. 2, p. 327-340, jul./dez., 2003.

ALVES, L. Educação a distância: conceitos e história no Brasil e no mundo. Revista Brasileira de Aprendizagem Aberta e a Distância, São Paulo, v. 10, n. 21, 2011.

BELLONI, Maria Luiza. Ensaio sobre a Educação a Distância no Brasil. Revista Educação e Sociedade, São Paulo, Ano XXIII, n. 78, abr. 2002. Disponível em: https://www.scielo.br/j/es/a/yvpWm7vFNqhpZYMtjn8kHZD/?format=pdf\&lang=pt. Acesso em: 31 jul. 2012.

BRANDÃO, Marise. A importância das TICs na educação. Revista Ponto Com, Rio de Janeiro, n. 8, maio., 2010. Disponível em: http://www.revistapontocom.org.br/ edicoes-anteriores-entrevistas/a-importancia-das-tics-na-educacao. Acesso em: 27 mar. 2020.

BRASIL. Decreto $n^{\circ} \mathbf{5 . 6 2 2}$ de 19 de dezembro de 2005. Regulamenta o art. 80 da Lei no 9.394, de 20 de dezembro de 1996, que estabelece as diretrizes e bases da educação nacional. Brasília, DF: Presidência da República, 2005. Disponível em: https:// presrepublica.jusbrasil.com.br/legislacao/109743/decreto-5622-05. Acesso em: 19 maio. 2021.

BRASIL. Lei $n^{\circ}$ 9.394, de 20 de dezembro de 1996. Estabelece as diretrizes e bases da educação nacional. Diário Oficial da União, Brasília, 20 dez. 1996. Disponível em: http:// www.planalto.gov.br/ccivil_03/leis/19394.htm. Acesso em: 19 mar. 2021.

CARVALHO, Adélia Honório de. Evolução histórica da Educação a Distância no Brasil: avanços e retrocessos. Trabalho de Conclusão de Curso (Pós-graduação em Educação: Métodos e Técnicas de Ensino, Modalidade de Ensino a Distância) -Universidade Tecnológica Federal do Paraná, Medianeira, 2013. Disponível em: http://repositorio.roca.utfpr.edu.br/jspui/ bitstream/1/4653/1/MD_EDUMTE_II_2012_01.pdf. Acesso em: 19 mar. 2021.

CARDOSO, Silva Helena; SABBATINI, Renato M. E.; BASTOS, H. M. Uma visão geral da educação à distância. São Paulo: Instituto Edumed para Educação em Medicina e Saúde, 2000. Disponível em: http://www.edumed.org.br/cursos/slides/

aula2-visao-geral/. Acesso em: 20 mar. 2020. 
FERREIRA, Rosa Gomes dos Santos; NASCIMENTO, Jorge Luiz do; PAIM, Luzimar Aparecida Borba; CARDOSO, Débora Ribeiro. Tecnologias em EaD e sua utilização no contexto de ensino de enfermagem. Revista Saúde e Desenvolvimento, São Paulo, v. 11, n. 9, 2017. Disponível em: https://www.uninter.com/revistasaude/ index.php/saudeDesenvolvimento/article/view/797. Acesso em: 13 abr. 2020.

DOURADO, Irismar de França et al. Uso da TIC no Ensino de Ciências na Educação Básica: uma Experiência Didática. Revista de Ensino, Educação e Ciências Humanas, São Paulo, v. 15, p. 357-364, 2014. Disponível em: https://revista.

pgsskroton.com/index.php/ensino/article/view/438. Acesso em: 13 abr. 2021.

HERMIDA, Jorge Fernando; BONFIM, Cláudia Ramos de Souza. A educação à distância: história, concepções e perspectivas. Revista HISTEDBR On-line, Campinas, n. 2, p.166181, ago., 2006. Disponível em: http://www.histedbr.fe.

unicamp.br/revista/edicoes/22e/art11_22e.pdf. Acesso em: 5 mar. 2020.

KENSKI, Vani Moreira. Tecnologias e ensino presencial e a distância. Campinas: Papirus, 2003.

MAIA, Carmem; MATTAR, João. ABC da EaD: a Educação a Distância hoje. 1. ed. São Paulo: Pearson Prentice Hall, 2007.

MIRANDA, G. L. Limites e possibilidades das TIC na educação. Sísifo. Revista de Ciências da Educação, São Paulo, n. 3, p. 41-50, 2007. Disponível em: http:// portaldoprofessor.mec.gov.br/storage/materiais/0000012617.pdf. Acesso em: 22 set. 2020. MOORE, M. G; KEARSLEY, G. Educação a distância: uma visão integrada. São Paulo: Thomson Learning, 2008.

MONTEIRO, C. G. O papel educativo dos meios de comunicação. CEPPG Revista, Goiás, v. 1, p. 171 - 183, mar., 2001. Disponível em: http://www.ipu.pt/ foumeia/3/ 3fi3.htm. Acesso em: 28 maio. 2012.

MORAN, José. Manuel. Como utilizar a internet na educação. Rev. Ciênc. Educ., São Paulo, v. 26, n. 2, 1997. Disponível em: http://revista.ibict.br/ciinf/article/view/ 700. Acesso em: 20 mar. 2020.

MORAN, José. Manuel. Os novos espaços de atuação do professor com as tecnologias. Diálogo Educacional, Curitiba, v. 4, n. 12, p. 1-9, 2004.

NUNES, Ivônio Barros. Noções de Educação a Distância. Revista Educação a Distância, Brasília, n. 4, p. 7-25, dez./abr., 1993. Disponível em: http://www.educa dores.diaadia.pr.gov.br/arquivos/File/2010/artigos_teses/EAD/NOCOESEAD.PDF. Acesso em: 20 mar. 2020.

PAESE, C. R. Educação a Distância (EaD) e o uso das tecnologias de informação e comunicação (TICs), baseada em ambientes virtuais de aprendizagem (AVA) algumas reflexões sobre a importância da tutoria on-line. Itinerarius Reflectionis, Goiás, v. 8, n. 1, 2012.

RODRIGUES, N. C. et al. Recursos didáticos digitais para o ensino de Química durante a pandemia da Covid-19. Research, Society and Development, São Paulo, v. 10, n. 4, 2021. 
SILVA, Renata Maldonado da. A Trajetória do Programa Telecurso e o monopólio das Organizações Globo no Âmbito do tele ensino no Brasil. Revista de Educação por Múltiplos Olhares II, Mato Grosso do Sul, v.19, n. 38, 2013. Disponível em: https:// periodicos.ufms.br/index.php/intm/article/view/2357. Acesso em: 10 mar. 2020.

SILVEIRA, A. P. et al. Uma breve revisão histórica do papel das videoaulas na EaD no Brasil. Working Papers em Linguística, Santa Catarina, v. 2, p. 53-66, 2010.

VILAÇA, M. L. C. Educação a Distância e Tecnologias: conceitos, termos e um pouco de história. Revista Magistro, Rio de Janeiro, v. 1, n. 2, p. 89-101, 2010.

Recebido em 19 de outubro de 2021 Aprovado em 23 de novembro de 2021 